\title{
TRANSGENERIDADE E CANDOMBLÉS: NOTAS PARA UM DEBATE
}

\author{
wanderson flor do nascimento ${ }^{1}$
}

DOI 10.26512/revistacalundu.v3i2.28957

\begin{abstract}
Resumo
Este artigo se propõe a sistematizar algumas ideias que potencializem de maneira produtiva a discussão nos terreiros de candomblé em torno da presença das pessoas transgêneras, buscando enfatizar os elementos internos da tradição, problematizando a ideia mesma de tradição, e alguns temas que são recorrentes no debate, como o corpo e as modificações corporais, a identidade as vestimentas e a atribuição dos cargos. Embora não se pretenda apresentar elementos conclusivos sobre o debate, objetiva-se oferecer elementos para que o debate aconteça sem uma colonização dos termos, a partir de teorias centradas das experiências ocidentais, sem deixarmos de considerar o caráter de acolhimento, histórico nos terreiros.
\end{abstract}

Palavras-chave: Transgeneridade. Candomblé. Tradição. Identidade.

\section{TRANSGENERIDAD Y CANDOMBLÉS: NOTAS HACIA UN DEBATE}

\begin{abstract}
Resumen
Este artículo tiene como objetivo sistematizar algunas ideas que potencien positivamente la discusión sobre la presencia de personas transgéneras en los Terreiros de Candomblé, buscando enfatizar los elementos internos de la tradición, problematizando la idea misma de tradición y algunos temas que son recurrentes en el debate, tales como el cuerpo y las modificaciones corporales, identidad, ropas y asignación de posiciones. Aunque no tenga la intención de presentar elementos concluyentes sobre el debate, tiene la intención de ofrecer elementos para que la discusión tenga lugar sin una colonización de términos, basados en teorías centradas en experiencias occidentales, sin dejar de considerar el carácter acogedor, histórico en los Terreiros.
\end{abstract}

Palabras-clave: Transgeneridad. Candomblé. Tradición. Identidad.

\footnotetext{
${ }^{1}$ Tata ria nkisi Nkosi Nambá. Professor de Filosofia e Bioética da Universidade de Brasília (UnB). Colíder do Grupo de Estudos e Pesquisas em Educação, Raça, Gênero e Sexualidades Audre Lorde (GEPERGES Audre Lorde - UFRPE/UnB/CNPq) e Membro do Núcleo de Estudos Afro-Brasileiros (NEAB - CEAM/UnB) e do Núcleo de Estudos de Filosofia Africana Exu do Absurdo (NEFA/UnB). Email:wandersonflor@unb.br
} 


\section{Palavras iniciais}

Um dos temas mais polêmicos na atualidade dos terreiros de candomblé é a experiência da transgeneridade ${ }^{2}$ : o fato de que pessoas que nasceram com uma genitália relacionada socialmente a um determinado sexo se identificarem existencialmente com o outro sexo ou, de outras formas, recusarem essa designação social do gênero ocorrida em seu nascimento. Esse fenômeno está ligado com o que os estudos sobre subjetividade chamam de "identidade de gênero"3, ou seja, como as pessoas experimentam sua presença no mundo através de relações de identificação (ou nãoidentificações) com imagens culturalmente construídas do masculino e feminino em relação aos corpos das pessoas, tencionando ideias naturalizadas do que significa ser homem e mulher e que ligação teriam essas ideias com os corpos em suas múltiplas experiências.

Não se trata, portanto, de uma questão que envolve a experiência sexual das pessoas, como se toda pessoa que vivencia, por exemplo, a transexualidade experimentasse sua orientação sexual na forma da homossexualidade. ${ }^{4}$

A experiência da transgeneridade enfrenta uma diversidade de tabus, preconceitos e violências nas sociedades ocidentais, que determinaram não apenas um papel, mas um corpo específico para ser vivenciado pelo gênero masculino e pelo

\footnotetext{
${ }^{2}$ Utilizo o termo "transgeneridade" em vez de "transexualidade", por entender que o primeiro é mais abrangente e incluir outras experiências e modos de viver, dentre os quais a experiência transexual é um deles. E, além disso, gostaria de me distanciar da possibilidade de ler a experiência da pessoa transgênera apenas em função de uma abordagem de uma "relacionalidade sexual", que a segunda expressão pode suscitar. Estou interessado na dimensão dos modos como as pessoas se relacionam consigo mesmas no mundo.

${ }^{3}$ Os estudos sobre identidade de gênero discutem a pluralidade das classificações relativas ao gênero em função da coincidência (ou não) da identificação do gênero experimentando pela pessoa e a identidade sexual (como macho ou fêmea da espécie). Quando a pessoa percebe seu gênero em coincidência com as determinações sociais sobre seu sexo, chama-se essa identidade de "Cisgênera" (ou seja, homens nascidos com pênis e aparelho reprodutor exclusivamente associados aos machos da espécie e mulheres nascidas com útero e vagina e aparelho reprodutor exclusivamente associados às fêmeas da espécie). Ao passo de que quando não há uma coincidência entre a experiência do gênero e o marco social do sexo, temos as mulheres e homens "Transgêneros" (isto é, homens nascidos com a genitália e aparelho reprodutor vinculados às fêmeas da espécie e mulheres nascidas com a genitália e aparelho reprodutor vinculados aos machos da espécie). Utilizarei aqui a distinção entre transgênero e cisgênero, tal qual foi difundida pela pesquisadora Julia Serano (2007, p. 33). As experiências transgêneras mais conhecidas para a realidade brasileira são a pessoa transexual e a pessoa travesti. Não tratarei aqui das chamadas experiências não binárias de gênero.

${ }^{4}$ Não é incomum vermos, por exemplo, mulheres transexuais lésbicas, ou seja, que se relacionam afetiva e/ou sexualmente com outras mulheres, transgêneras ou cisgêneras. Um documentário que nos mostra um exemplo de uma mulher transexual lésbica aparece em "Amanda e Monick" (Dir.: André da Costa Pinto, 2008, 20 min), no qual vemos a experiência de Monick, uma transgênera que vive uma relação lesbiana.
} 
gênero feminino. Estes gestos de recusa da experiência trans são determinados por atuação de uma cisnormatividade, isto é, uma lógica social que naturaliza e prescreve a experiência cis como a única correta. E, mais recentemente, vemos um recrudescimento do preconceito e suas expressões violentas contra as pessoas que vivem a experiência da transgeneridade (que chamarei doravante de pessoas trans ${ }^{5}$ ), em parte em função da maior visibilidade - resultado das lutas dos movimentos Trans* - que os últimos anos proporcionaram às pessoas que vivenciam a transgeneridade.

Essa questão, até pouco tempo silenciada nos terreiros de candomblé, tem agora eclodido intensamente, de maneira que já não se pode mais se furtar às questões que ela traz para o interior de nossas comunidades. Minha intenção aqui não é resolver a questão da presença da transgeneridade nos terreiros de candomblé, mas oferecer alguns elementos que subsidiem o debate, que se faz necessário e que se situa polemicamente nos terreiros. A polêmica se instaura quando as posições que sustentam que os terreiros aparecem como espaços transfóbicos enfrenta a posição de que a vontade das pessoas trans estariam desrespeitando a tradição dos terreiros que teria papéis definidos para homens e mulheres - entendidos em uma abordagem que se aproxima do biologicismo. Os elementos que trarei estão completamente ligados com minha percepção e experiência - como homem candomblecista cis que se posiciona pública e frontalmente contra as transfobias - sobre a questão dentro e fora dos terreiros de candomblé. ${ }^{6}$

Os debates - com fervorosas defesas e recusas - têm sido bastante intensificados nos últimos anos, sobretudo através das redes sociais, mas também em encontros e seminários dos povos de terreiros. Algumas pesquisas também foram realizadas como parte do debate ou sobre o debate; e grande parte delas se equivoca, em minha percepção, ou por utilizar um referencial teórico forâneo aos terreiros, de modo que haverá sempre um ruído para as comunidades candomblecistas por não se identificarem com os discursos acionados para discutir a questão, ou por não levarem em consideração as complexas redes de sociabilidade que se instalam no interior dos terreiros.

Como são muitos os elementos que usualmente se utilizam para condenar a presença da transgeneridade nos terreiros de candomblé, trarei aqui apenas os elementos

\footnotetext{
${ }^{5}$ Me referirei às pessoas cisgêneras como pessoas cis.

${ }^{6}$ Sou iniciado no Candomblé de Angola desde 1979. E venho trabalhando com os estudos sobre a diversidade de gênero desde o final da década de 1990.
} 
que acho, nesse momento, relevantes para problematizar essa condenação e, ao mesmo tempo, interpretar algumas possibilidades de resistência desde referenciais mais internos aos terreiros. Quero manifestar, também, minha posição sobre a necessidade do debate, buscando pensar em criação de espaços para a presença pacífica das pessoas trans nos terreiros, que foram constituídos historicamente como espaços de cuidado, acolhimento e equilíbrio (GUIMARÃES, 2003) de pessoas que tiveram suas experiências socialmente marginalizadas e agredidas.

\section{Situando o debate}

A presença de pessoas transgêneras no candomblé não é nenhuma novidade. $O$ que parece "novo" é o debate sobre quais lugares as pessoas transgêneras podem ocupar dentro dos terreiros e sobre as consequências das eventuais transformações corporais (que podem ir da inserção de silicone até as cirurgias de redesignação sexual) para a presença das pessoas trans nas rotinas de um terreiro de candomblé.

O debate está organizado, normalmente, em torno de quatro dimensões: o lugar do corpo no terreiro e em suas dinâmicas rituais; o "direito" à modificação corporal e seus impactos na rotina da pessoa que fez esta modificação, durante sua presença no terreiro; a questão das vestimentas no cotidiano do terreiro; e, por fim, quem pode ocupar determinados cargos ou funções dentro do terreiro. Cada uma dessas dimensões está vinculada com pressuposições, nem sempre debatidas o suficiente, sobre os modos como as tradições africanas instaladas no terreiro pensam os fenômenos relativos a cada uma dessas dimensões.

Sobre a primeira dimensão, normalmente se evoca a ideia de que o corpo é morada do orixá, vodum ou inquice (MANDARINO, GOMBERG, 2013, p. 200). E, assim sendo, não pertence exclusivamente à pessoa que o habita, seja ela trans ou cis. Ao corpo estariam associadas uma série de interdições, inclusive algumas conhecidas como quizilas ou ewós, de modo que o corpo demandaria uma série de cuidados específicos que seriam determinados no interior da própria tradição dos terreiros (BARROS; TEIXEIRA, 2000). Os banhos de ervas, as oferendas rituais que tocam o corpo (como ebós e sacudimentos), etc. seriam parte desses cuidados e estariam pensados, em determinados casos, especificamente para os corpos "naturalmente" 
femininos ou masculinos. E uma vez que a experiência trans não participaria dessa tradição, estaria tencionada com ela.

A segunda dimensão é dependente da primeira. A modificação dos corpos mudaria, também, a posição que esses corpos ocupariam na dinâmica do terreiro, causando uma espécie de presença estranha do corpo na comunidade. Esse é o motivo pelo qual muitas casas não permitem que as pessoas iniciadas tatuem os corpos, uma vez que o corpo do iniciado é identificado pelas divindades e pela comunidade do modo como se apresentava no momento da iniciação.

A terceira dimensão (que se relacionará com a última das dimensões), parece supor que a identificação dos lugares e papeis na comunidade são também expressos pelos modos como as pessoas pertencentes à comunidade se vestem. Há roupas específicas para mais velhos, mais novos, para determinadas situações e ritos e, sobretudo, para mulheres e homens. E essa especificidade estaria incrustrada na tradição, não sendo facilmente mutável.

A última dimensão supõe que haja uma espécie de divisão sexual da atividade ritual. E essa divisão sexual não estaria vinculada com a expressão social do sexo das pessoas, mas de sua apresentação "natural”, biológica. Para essa percepção haveria uma corporalidade "naturalmente" feminina ou masculina. E várias das funções importantes do terreiro só poderiam ser desempenhadas por alguém que tivesse um tipo ou outro de corpo.

Por outro lado, uma parte das discussões sustenta que essas dimensões estão atravessadas de transfobia, pois não reconheceriam o direito das pessoas trans exercerem suas atividades no terreiro em consonância com o modo como elas se identifiquem, sendo obrigadas a desempenharem papéis, a vestirem roupas a utilizarem seu corpo de acordo com as normas cisgêneras da sociedade.

Para o meu entendimento, todas essas dimensões e posições carregam equívocos de interpretação da experiência da vida comunitária no terreiro e sobre o que significa tradição. Penso que quando reconsideramos os aspectos africanos componentes da tradição e da rotina dos terreiros, sobre a constituição e o funcionamento da comunidade, temos outros elementos para o debate. E, nesse contexto, gostaria de trazer alguns elementos que nos ajudem a promover essa reconsideração para que a discussão se encaminhe para termos mais próximos ao 
histórico de relação que os terreiros mantiveram com as maneiras de lidar com as exclusões sociais no Brasil.

\section{Primeiro elemento: Tradicionalizando a tradição}

O primeiro elemento que eu gostaria de trazer é a discussão sobre a Tradição. Os candomblés são comunidades tradicionais. Isso quer dizer que nossas práticas e olhares do mundo são orientados pelo viés da tradição. Mas o que seria a tradição? Muitas vezes somos tentados a pensar em tradição como sendo aquilo que não muda, que permanece o mesmo de geração em geração, sendo, portanto, estática. Entretanto, as noções africanas de tradição têm muito mais a ver com a dinâmica da transmissão do que com a estática de uma experiência conservada (AGUESSY, 1980).

A palavra tradição, tal como a utilizamos, é advinda do latim tradere que significa transmitir; desse modo, tradição seria um sinônimo de transmissão. Transmissão do quê? Do que é realmente importante (INIESTA, 2010, p. 16-20). Tradição significa que ensinamos e aprendemos o conhecimento e práticas fundamentais e básicos para a compreensão de nossa existência e para os parâmetros de avaliação de nossas ações. Até aqui, parece que a definição é pacífica; entretanto, o problema se coloca quando precisamos saber o que é fundamental ou basilar para compreender nossa existência e o que necessitamos para orientar nossas ações.

Se observarmos as quatro dimensões enunciadas antes, o que nelas estaria de fato relacionado com o que precisamos para viver comunitariamente? Se o corpo é templo do orixá, vodum ou inquice, isso significa que o templo deva permanecer sempre do mesmo modo? Quais os limites para o que pode ser modificado em um corpo para que ele siga permanecendo templo das divindades? As vestimentas utilizadas permaneceram as mesmas do decorrer dos tempos? O que nelas se modifica e qual o sentido dessas modificações? As divisões das tarefas do terreiro, em função do tipo de corpo, são universais? Permanecem invariavelmente a todo o tempo? Todas essas questões podem ser colocadas para relacionar o que entendemos como tradição e o que esse entendimento impacta do cotidiano dos terreiros em relação com o que se pensa sobre o que permanece no tradicional.

Outra questão fundamental frente à pertença a uma comunidade tradicional é que nem tudo na comunidade tradicional é essencialmente tradicional. Diferenciar o que 
é acessório e o que é fundamental na tradição se transforma, então, em nosso desafio básico. Sabemos que a noção de ancestralidade é um desses eixos fundamentais das tradições africanas que nos foram legadas nos candomblés. E essa noção de ancestralidade, obviamente, está vinculada com a noção de descendência e esse ponto coloca em questão a noção de reprodução, questão considerada importante para parte da discussão em torno da transgeneridade.

Não sei se nos cabe questionar os motivos pelos quais a ancestralidade e sua projeção na forma da reprodução se tornou um elemento basilar da tradição. Provavelmente isso não importe. Mas o que é fato, é que não podemos, simplesmente, abrir mão dessa noção em termos tradicionais.

E é na discussão sobre a ancestralidade que a reprodução coloca de maneira incontornável os papéis do macho e da fêmea da espécie. Para a tradição só podemos experimentar um desses papéis. E, a partir desses papéis, outros papéis sociais são determinados, com interditos gerais a qualquer dos papéis. Algumas funções sociais só podem ser desempenhadas por homens e outras por mulheres e, como para nossas comunidades tradicionais não há uma distinção radical entre o espaço ritual e o restante da vida social, isso se transfere para os cultos. Há cultos vedados a homens e há cultos vedados a mulheres. Há papeis nos cultos vedados a homens e há outros papéis vedados às mulheres.

E aqui começa nossa dificuldade em pensar essa questão no que diz respeito às comunidades dos candomblés: Qual o sentido dessas interdições? É só para ser coerente ao ciclo da ancestralidade e da reprodução que funda papéis? Suponhamos que sim. Se esse for o caso, naturalmente nenhuma mulher transgênera poderá desempenhar um papel destinado a uma mulher cisgênera, já que a primeira é terminantemente impossibilitada de procriar, de constituir descendência biológica na forma do parir. $\mathrm{O}$ mesmo acontecendo com homens trans, que estariam impossibilitados, como os homens cis, de inseminarem e fecundarem um óvulo.

Mas se o critério for esse, logicamente deveríamos interditar que mulheres e homens estéreis ocupassem qualquer papel em qualquer culto, uma vez que essas pessoas também são impossibilitadas de procriar. Isso parece não fazer qualquer sentido (ou pelo menos não vejo ninguém que se disponha a interditar uma mulher estéril ou uma mulher idosa que não teve filhos biológicos por qualquer outro fator além da esterilidade de participar de qualquer culto que seria destinado a qualquer outra mulher). 
Talvez devêssemos nos atentar para a imagem de família que aparece na tradição africana no Continente Negro e na Diáspora: A família é sempre expandida e a função de descendência não é de um indivíduo, mas da comunidade familiar. Nesse cenário, a presença de uma pessoa trans não desestabilizaria o critério da descendência, assim como também não o faria uma pessoa sem filhos por qualquer outro motivo (como esterilidade ou decisão voluntária).

Parece, então, que do ponto de vista do fundamento tradicional da ancestralidade não se sustentaria, por princípio, a vedação de funções destinadas a pessoas cisgêneras a pessoas transgêneras.

\section{Segundo elemento: sacralizando o corpo}

Outro ponto comumente utilizado para instituir algumas tensões em torno da presença das pessoas trans nos candomblés são as modificações corporais. Estas transformações são diversas e vão desde a introdução de silicone para a construção de seios até a cirurgia de readequação sexual. Ao que parece, o fundamento tradicional para essa tensão é o fato de que para as percepções de mundo africanas que herdamos nos candomblés não há a dualidade entre corpo e alma (BARROS; TEIXEIRA, 2000, p. 110), e se percebe o corpo da pessoa iniciada como um dos lugares onde habitam as divindades, "um altar vivo" da divindade, um “corpo-altar” (JAGUN, 2019, p. 77).

Nesse contexto, uma modificação implicaria na transformação (muitas vezes vista como uma violação) desse corpo-morada, que por vezes se lê como templo. Acho esse um dos mais frágeis argumentos por duas razões: a primeira é que um templo não deixa de ser um templo simplesmente porque passou por uma reestruturação. É sua funcionalidade e a relação que estabelecemos com ele que faz de um determinado espaço um templo. A segunda é que nós somos sujeitos/as a diversas modificações corporais cotidianamente (desde extrações dentárias, passando por cirurgias diversas que extirpam partes do corpo - como vesículas biliares, rins, membros superiores ou inferiores, úteros, ovários, amigdalas, apêndices cecais, seios etc. - até modificações estéticas como lipoaspirações e aplicações estéticas de silicone no corpo). E, voluntárias ou não, essas modificações impactam a "configuração inicial” do corpo.

Entretanto, como para os candomblés, o corpo não é uma propriedade individual, devemos lembrar que é sempre necessário negociar com os "donos da casa" 
a sua reforma ou modificação e que também nem todas as modificações ou cirurgias são isentas de riscos. Por isso, como várias outras atitudes importantes que tomamos quando somos parte de um terreiro, devemos consultar as divindades por meio dos oráculos e ouvir o que elas têm a dizer. E a resposta, como a qualquer consulta pode nos encorajar a tomar uma decisão, ou não.

Se um inquice, orixá ou vodum autoriza que alguém extraia um dente siso, porque motivo não permitiria que alguém retirasse seu pênis ou seus seios ${ }^{7}$ ? Se autoriza a colocação de silicone estético num seio pequeno de uma mulher ou no rosto de quem quer que seja, se autoriza redução de estômago, se autoriza a lipoaspiração, porque não autorizaria a construção de um pênis protético em um homem trans?

Eu suspeito que essa suposição de interdição venha da maneira ocidental de pensar o gênero colado com o sexo, fazendo uma espécie de analogia entre gênero-alma e sexo-corpo. Só que acho que aí incorremos num erro grave. Como já chamei a atenção, não há um dualismo entre corpo e alma para nossa tradição como há para a tradição ocidental. Uma prova disso é que quando uma mulher cisgênera "recebe" em seu corpo a uma divindade entendida como 'masculina', como Nkosi ou Ogum, toda a comunidade tratará essa mulher como um homem, pois quem está ali não é mais a mulher, mas a divindade. Há um trânsito que não separa corpo de alma e nem determina que gênero atravessa um determinado corpo (BOTELHO, STADLER, 2012, p. 184185). Para a tradição o corpo só é corpo masculino ou feminino em função da reprodução. Se a reprodução não estiver em jogo, como encarar o corpo? Essa é uma questão que devemos, coletivamente, tentar pensar.

\section{Terceiro elemento: compreendendo os elementos da identidade}

Se a epistemóloga nigeriana iorubá Oyèrónkẹ́ Oyěwùmí (1997) tiver razão, a ideia de que o gênero seja um elemento fundamental da identidade de qualquer pessoa é oriunda do ocidente. Segundo esta abordagem, a identidade de alguém, mesmo fora de contextos reprodutivos, é completamente determinada pelo tipo sexuado de corpo dessa pessoa. Uma mulher não é apenas uma fêmea da espécie, um homem não é apenas um macho da espécie: toda a sua identidade é atravessada por sua anatomia genital,

\footnotetext{
7 É fundamental notar que nem toda pessoa trans deseja fazer a cirurgia de transgenitalização (de modificação da genitália, também chamada de redesignação sexual) ou mastectomia.
} 
tornando o sexo biológico um fundamento incontornável da identidade, mesmo quando se possa pensar que os papéis sociais definidos para os tipos generificados de corpos tenham sido construídos culturalmente.

Esta importância do corpo sexuado para a identidade das pessoas seria também presente na organização das sociedades, de modo que haveriam papeis com lugares diferentes de prestígio, conformando o patriarcado, que confere socialmente lugares hierarquicamente superiores ao grupo dos homens e de desprestígio ao grupo das mulheres (OYĚWÙMÍ, 1997, p. xii).

Oyěwùmí sustenta que essa ideia não era presente entre os povos iorubás antes dos contatos coloniais com a Europa. Para esta autora, os tipos sexuais dos corpos só eram frisados no contexto da reprodução e não apontavam nenhum tipo de relação de poder ou lugar importante nas relações sociais (OYĚWÙMÍ, 1997, p. 12-13). Para ela, os tipos de corpos apresentados por obinrin e okùnrin ${ }^{8}$ seriam melhor entendidos, para os povos iorubás, como expressando uma "distinção sem diferença social" (OYĚWÙMÍ, 1997, p. 36). E ela, embora não faça nenhum tipo de generalização em relação a todos os povos africanos em sua análise, nos conta que esta ausência não era, no continente africano, exclusiva dos povos iorubás, podendo ser encontrada em outras sociedades africanas (OYĚWÙMÍ, 1997, p. xiv).

A autora iorubá nos conta que, em contraposição à organização generificada das sociedades ocidentais, os iorubás se estruturavam em torno do princípio da senioridade, isto é, da antiguidade relativa à idade cronológica, de modo que quanto mais velha era uma pessoa, mais prestígio e poder ela tinha em relação a quem era mais jovem (OYĚWÙMÍ, 1997, p. 40-43). E o fato de que a pessoa mais velha ou mais jovem fosse um macho anatômico ou uma fêmea anatômica não era determinante para os lugares de poder e hierarquia antes da colonização. Isso, porque, para ela, o corpo - e nem o gênero - foram "o fundamento do pensamento e da identidade sociais [iorubás]" (OYĚWÙMÍ, 1997, p. x).

Estas discussões podem nos auxiliar a entender os motivos pelos quais, por um lado, as mulheres e pessoas homossexuais sempre puderam ocupar lugares de liderança nos terreiros, porque seguiam o trajeto de alcance dos lugares de poder e prestígio, isto

\footnotetext{
8 Obìnrin e okùnrin são as palavras iorubás que, respectivamente, se referem às pessoas com os corpos sexuados de fêmea e macho da espécie humana, em idade adulta. Oyěwùmí (1997, p. xii) traduz o primeiro termo como "fêmea anatômica" ou "anafêmea" e o segundo como "macho anatômico" ou "anamacho".
} 
é, ser "mais velha/o", e que sua identidade de gênero não fora historicamente uma questão. Por outro lado, mostra também os motivos pelos quais o terreiro tem mostrado uma certa resistência de discutir a presença das pessoas trans na comunidade em termos de identidade de gênero, uma vez que o gênero não havia antes sido pensado como elemento constitutivo das identidades das comunidades candomblecistas, mas era um elemento entre outros nas histórias de vidas das pessoas. O núcleo da identidade fora definido pela senioridade nos terreiros e pela própria pertença à comunidade.

Embora essas informações não me pareçam suficientes para impedir ou resolver os conflitos, talvez nos ofereçam elementos para pensar alguns motivos pelos quais as discussões que surgem, por exemplo, ao introduzir categorias das teorias queer para pensar as experiências dos terreiros enfrenta uma série de tensões, pois parte de elementos "forâneos" para esse núcleo da organização social das comunidades candomblecistas.

Isso não quer dizer, por outro lado, que estas abordagens teóricas estrangeiras precisem ser excluídas do debate sobre a experiência da transgeneridade nos terreiros, mas que devem ser sopesadas em sua relação com as outras abordagens que a tradição manteve e construiu nos terreiros, incluindo as complexas, diversas e multifacetadas maneiras de se estabelecerem relações entre homens e mulheres, uma vez que os terreiros se constituíram não antes da colonização, mas durante seu processo e, de certa forma, em uma relação com ela, mesmo que seja a de resistência.

\section{Quarto elemento: Repensando o simbólico}

A questão mais frágil, e nem por isso menos polêmica, na discussão sobre a transgeneridade é, sem dúvidas, a problemática das vestimentas. Aos modos de se vestir no terreiro ultrapassam a função de agasalhar, recobrir, esconder ou proteger o corpo. As roupas compõem as tramas simbólicas por meio das quais valores, saberes e crenças se expressam, além de serem marcadores estéticos dos modos como os terreiros entendem as relações entre corpo e experiência (SOUZA, 2007, p. 8). Esta dimensão faz com que a preocupação com as roupas seja uma marca valorativa nos terreiros de candomblé. Neste contexto, é possível afirmar, que "as roupas são comunicadoras e contadoras de histórias, exercendo papeis de marcadores sociais, culturais e também religiosos" (PEREIRA, 2017, p. 60). 
Estes marcadores são de extrema relevância na prática cotidiana dos terreiros, pois expressam, nos códigos das vestimentas, diversos lugares na organização de cada casa ou tradição. Posições na hierarquia, faixas de idade de iniciação, cargos ou funções do terreiro, a situação de uma determinada prática ou ritual estão inscritos nas roupas. A posição de um laço, torço, o tipo de tecido ou o formato da roupa etc. dizem coisas sobre quem as usa e sobre o que se passa no terreiro. E esses ditos nas vestimentas foram construídos e enunciados no interior da tradição de cada terreiro.

Uma das divisões usuais, além daquelas que apontam para a idade ou hierarquia no terreiro, é a que aponta para a vestimenta feminina ou masculina. Ora carregando sentidos estéticos e identitários, ora carregando sentidos rituais, as vestes contam sobre funções que os corpos lidos como femininos e os corpos lidos como masculinos ocupam no terreiro. Usualmente, mulheres usam saia(s), anáguas, calçolão, batas, camisus, pano da costa e torço, ao passo que homens usam calças e batas e algum adorno de cobertura da cabeça, como os equetés ou boinas. Apesar de haver variações nesses modelos, o básico se mantém.

Também as divindades se vestem de acordo com esse imaginário relativo à divisão sexual, não obstante que existam casos em que algumas divindades entendas como masculinas possam vestir saias, saiotes e anáguas, a depender da tradição do terreiro.

Entretanto, apesar de este estabelecido padrão de vestimentas, é sabido que ele é convencionado e responde a imaginários e não a atos meramente rituais. Um dos exemplos deste processo é o fato de que, muitas vezes, as mulheres e divindades entendidas como femininas vestem roupas que seguem o estilo baiana, que não apenas não é africano, mas aponta para a estética da elite colonial que habitou os primeiros séculos brasileiros. O mesmo se passa com o uso dos tecidos bordados em estilo Richelieu, bastante usados nos terreiros.

Não há nada essencial e imutavelmente masculino ou feminino em vestes. $\mathrm{O}$ que há são convenções que podem se modificar no tempo, espaço e circunstâncias (SOUZA, 1987). Muito do que conhecemos como vestimentas tradicionais foram trazidas para o interior das tradições em mediações com sentidos de outros lugares não africanos. O que podemos perceber é que há intensas negociações sobre o que se quer transmitir com o uso de determinada vestimenta. Embora o que as roupas simbolizem 
esteja já presente no interior das comunidades de terreiro, o modo como essa simbolização se dá, parece aberto a discussões coletivas.

Em minha percepção, a problemática das vestimentas parece ser o campo em que se coloca de maneira mais nítida a possibilidade de uma discussão sobre o modo como a identidade de gênero é experimentada nos terreiros, sobretudo porque a grande maioria das questões que estão envolvidas nos modos de vestir não são vinculadas a fundamentos rituais.

Por outro lado, essa questão parece ser tratada de modo essencializado por parte das pessoas que reivindicam poder se vestir em conformidade com sua identidade de gênero. Se no cotidiano fora do terreiro uma mulher transgênera não precisa vestir saias ou vestidos obrigatoriamente, por que isso deveria acontecer no terreiro? As vestimentas precisam reificar as identidades? Ou elas também podem ser elas mesmas pensadas desde outras lógicas que não as binárias? Talvez o fenômeno do vestir-se nos terreiros possam servir de boa base para que a discussão possa acontecer, sem cairmos em essencialismos binários que são estranhos às tradições dos candomblés e, em certa medida, ao próprio debate mais politizado das identidades de gênero.

\section{Quinto elemento: Situando as escolhas e os cargos}

O último elemento que eu gostaria de trazer para a discussão é talvez um dos mais complexos e envolve a presença das pessoas nos cargos na organização e hierarquia dos terreiros. Os terreiros são organizados em torno de uma complexa teia de funções que reproduzem tanto uma estrutura familiar como uma série de cargos que se vinculam a imagens de senioridade que circulam nos terreiros (LIMA, 2003, p. 53-104).

Essa estrutura não apenas organiza, como também distribui o poder no interior da comunidade do terreiro. Começando pela liderança maior, a sacerdotisa ou sacerdote principal da casa, até às aspirantes à iniciação, uma série de relações de poder circula no terreiro e muitas dessas relações se vinculam com os lugares que ocupam os cargos. Depois da mãe ou pai de santo, no vocabulário corrente, os mais conhecidos cargos são os das pessoas que não entram em transe e que são chamados de muitos modos nas diferentes tradições dos candomblés, como, por exemplo, Ekeji, Makota, Ogã, Kambondo etc. 
Enquanto o cargo mais alto, da sacerdotisa ou sacerdote principal, independe do gênero, da identidade de gênero e da orientação sexual da pessoa que o ocupe, estes outros cargos que listei (e alguns outros), são distribuídos no terreiro em função do sexo das pessoas. Tomando os exemplos acima, os cargos de Ekeji (em alguns candomblés de origem iorubana) e Makota (nos candomblés Angola/Congo) são exclusivamente desempenhados por mulheres, ao passo que Ogã (nos candomblés de origem iorubá) e Kambondo (nos candomblés de línguas bantas) são cargos exclusivamente masculinos.

Embora diversos cargos importantes não façam distinção relativas ao sexo, um determinado número deles o faz. E é em relação a estes que habitam os conflitos. Um homem trans poderia ser um Ogã ou um Kambondo? Uma mulher trans poderia ser uma Ekeji ou Makota? Poderiam ser criados cargos específicos para pessoas trans? Estas são algumas das questões mais polêmicas diante da presença das pessoas trans nos terreiros hoje.

Mais do que responder com um sim ou um não a essas questões, penso que precisamos pensar na lógica da atribuição dos cargos, mantida nos terreiros. Via de regra, as funções e cargos mais importantes não são escolhidos pelas pessoas que os ocupam. Elas apenas podem aceitar ou não o cargo que lhes é definido. Com um exemplo pessoal, posso dizer que eu não escolhi entrar em transe em vez de poder ser um Kambondo e tocar os atabaques, não escolhi ser do nkisi Nkosi, divindade da guerra e da tecnologia e, tampouco escolhi os cargos que exerço - de Tata ria Nkisi de meus descendentes e de Tata Ndenge de minha casa.

Assim, podemos dizer que o essencial do que acontece sobre a presença de uma determinada pessoa em um terreiro não é escolhido por esta mesma pessoa. Sobre condição de entrar ou não em transe, há diversas interpretações nas tradições, quase todas elas se remetendo a um período anterior ao nascimento. Já a decisão sobre a quase totalidade dos cargos cabe às divindades, que expressam suas decisões pelos oráculos ou, em determinados casos, através de sua própria expressão no transe em iniciadas/os rodantes (normalmente naquelas/es com um determinado tempo de iniciação).

Embora possamos discutir se cada cargo específico é definido pela comunidade, por quem exerce o sacerdócio mais alto do terreiro ou pela divindade, o que temos como fenômeno regularmente observado é que não há a escolha de ter/exercer um determinado cargo por quem o exercerá. Há pessoas que passarão todo o seu ciclo iniciático sem ter nenhum cargo, sem que isso comprometa sua importância na 
comunidade, sobretudo em razão de seu tempo de iniciação e conhecimento acumulado sobre o funcionamento do terreiro.

Parte do debate em torno dos cargos parece fazer parecer que alguma pessoa seja ela cis ou trans - pode escolher, de modo geral, que cargos vá desempenhar no interior do terreiro. Embora algumas funções possam ser direcionadas a quem tenha uma determinada aptidão afim a tais funções, esta não é a regra praticada nos terreiros. E embora se possa questionar essa aparente divisão sexual dos cargos, isso não modifica o caráter não volitivo, em relação a quem os exercerá, da atribuição destes cargos. Se considerarmos essa dimensão, outros termos deveriam fazer parte do debate nos terreiros.

Penso que esta seja uma das mais importantes formas pelas quais os terreiros constroem sua maneira não excludente de lidar com todas as pessoas: não deixar que posições individuais de quem exerça uma determinada função ou cargo se sobressaia a elementos rituais ou comunitários. Nenhum homem cis poderá escolher se é ou não "rodante" (nome usual nos candomblés para as pessoas que entram em transe), assim como não poderá escolher se exercerá um cargo a ou b. E essa regra também se aplica às pessoas trans que pertençam aos terreiros; e não porque elas sejam pessoas trans, mas porque a ninguém é oferecida uma regra diferente. Esta é a base de um tratamento igualitário.

O grande desafio que se coloca para o debate, quando a dimensão da escolha e dos cargos é reposicionada é pensar além do tratamento igualitário, mas em termos de equidade, isto é, tratar as pessoas em função de suas diferenças, rumo a um tratamento equilibrado em razão dessas diferenças. E cada casa, cada tradição tem seus próprios termos para pensar a dimensão da equidade, considerando o modo como a diferença é tensionada na comunidade.

\section{Considerações finais}

O candomblé nasce no Brasil como uma experiência entremundos. Com isso, quero dizer que ele se configurou e se configura como uma reconstrução, com elementos africanos e indígenas brasileiros, de uma experiência para a preservação da 
memória, mas em circunstâncias diferentes daquelas vivenciadas no continente africano anteriormente à colonização escravagista.

Por isso, os candomblés precisam lidar com a experiência ocidental que foi imposta aqui no Brasil, de modo colonial. Falamos o português, nos terreiros, juntamente com outras línguas africanas. O entorno dos terreiros é conformado pela construção da sociedade nacional brasileira, cuja formação foi totalmente colonial. Seria estranho pensar que o terreiro pudesse ser uma bolha que se isolasse totalmente de todos esses elementos que o circundam.

Uma das coisas que entraram no terreiro, em sua construção, foi a divisão generificada da experiência, tal como o ocidente a entende. Se Oyèrónkẹ́ Oyěwùmí (1997) e suas fontes e interlocutoras textuais e orais tiverem razão - e eu penso que tenham -, a experiência dos povos iorubás (e de alguns outros povos africanos) não era regulada pelo gênero antes da colonização e do tráfico escravagista. Parte dos valores e crenças desta época anterior ao malfadado encontro com os colonizadores e traficantes chegou aos terreiros. Mas a experiência ocidental chegou junto, trazendo também seus valores e crenças.

E é exatamente no Ocidente, que, ao termos o gênero como fator importante da identidade do ser homem ou mulher (descritos por uma cisnormatividade), que a problematização da experiência trans e a transfobia se tornam um problema. E a recusa desta experiência pode adentrar nos terreiros, quando já não adentrou. Isso se dá por que, conforme nos informa Kaio Lemos (2019, p. 129-130),

Mesmo que o candomblé seja uma religião conhecida pelos processos de inclusão social, como no caso dos homossexuais e lésbicas, ainda assim essa religião está ancorada nas bases do binarismo. Ou seja, no entendimento de um homem e uma mulher biológicos, mais especificamente de mulheres de vagina e homens de pênis, parecendo prevalecer esse corpo biológico e não mais a essência das pessoas.

Entretanto, parece que esse é um problema que adentra os terreiros porque essa base binarista é já colonial em relação às experiências africanas no passado. Se hoje encontramos relatos de agressões simbólicas ou físicas a pessoas trans nos terreiros, devemos ao fato de que há um conflito entre essa imagem estática de tradição que foi incutida, naturalizando esse binarismo ocidental, como se universal fosse.

E aqui nos encontramos diante de um grande desafio. Evitar que os terreiros se tornem transfóbicos, como o é o Ocidente, mas sem perder usas bases africanas. Penso 
que há um conflito também com os termos que circundam o debate, e raramente o fazemos a partir das matrizes africanas de nossa tradição. Como a cisnormatividade é parte da constituição ocidental do pensamento, precisamos retomar nossas origens africanas para fazer o debate de modo menos perigoso para a própria tradição. Na questão que nos interessa, a dificuldade dos candomblés em lidar com a transgeneridade é uma questão, de fato, advinda dos fundamentos africanos dos terreiros, ou é uma expressão da transfobia ocidental que busca justificativas na tradição?

Por outro lado, em que medida não confundimos a importância que os povos africanos dão à reprodução para a manutenção da vida da espécie com a distribuição de papéis comunitários que não estão relacionados com a reprodução? Será que não se pode correr o risco de fazer uma leitura biologicista (nos termos ocidentais) das próprias tradições africanas? Penso que é importante fazer o debate, de modo crítico, considerando os elementos das próprias tradições africanas pré-coloniais que herdamos para não incorrer naquilo que Claudenilson Dias (2017) chamou de "exclusão e pseudoaceitação" das pessoas trans.

O debate é complexo e está por ser desenvolvido. Mas penso que dois alertas importantes precisam ser feitos sobre a necessidade do debate. O primeiro é que tenhamos o cuidado de não corroborar com a hegemonia de discursos ocidentais como elementos para pensar a experiência dos terreiros. As tradições africanas têm ferramentas potentes para lidar com os diversos conflitos no interior das comunidades e precisamos retomá-las, em vez de naturalizar uma imagem de uma tradição atrasada e estática com a qual precisamos lidar.

O segundo é relembrar que a dimensão da comunidade inclui também inquice, vodum e orixá. Raramente consultamos essas divindades para poder compreender o que acontece na comunidade em relação à experiência das pessoas trans. Em não ouvi-las, perdemos uma oportunidade importante de entender como a própria tradição lida com essas experiências que lhe são diferentes e corremos o risco de meramente reproduzir valores externos que pensamos ser essencialmente e estaticamente tradicionais.

Portanto, retomar os debates, tendo as componentes africanas pré-coloniais como preponderantes e ouvindo as divindades pode oferecer alternativas interessantes para conduzir esta questão que é problemática em função das maneiras como o ocidente construiu as imagens do que seja ser homem e do que seja ser mulher e que tem provocado sofrimentos de tantas ordens na vida de tantas pessoas. 


\section{Referências Bibliográficas}

AGUESSY, Honorat. "Visões e percepções tradicionais". In: SOW, Alpha I et al. Introdução à Cultura Africana. Lisboa: Edições 70, p. 95-136, 1980.

BARROS, José Flávio Pessoa de; TEIXEIRA, Maria Lina Leão. “O código do corpo: inscrições e marcas dos orixás”. In: MOURA, Carlos Eugênio Marcondes de. (Org.). Candomblé: Religião do Corpo e da Alma: Tipos psicológicos nas religiões afrobrasileiras. Rio de Janeiro: Pallas, p. 103-138, 2000.

BOTELHO, Denise; STADTLER, Hulda Helena Coraciara. "Os orixás fazem gênero dentro dos rituais". Revista da Associação Brasileira de Pesquisadores/as Negros/as $(A B P N)$, v. 3, n. 7, p. 171-190, jun. 2012. ISSN 2177-2770. Disponível em: <http://www.abpnrevista.org.br/revista/index.php/revistaabpn1/article/view/371> Acesso em: 14 out. 2019.

DIAS, Claudenilson da Silva. Identidades Trans* e Vivências em Candomblés de Salvador: entre aceitações e rejeições. Dissertação (Mestrado em Estudos Interdisciplinares sobre Mulheres, Gênero e Feminismo). Programa de Pós-Graduação em Estudos Interdisciplinares sobre Mulheres, Gênero e Feminismo. Salvador: Universidade Federal da Bahia, 2017.

GUIMARÃES, Marco Antonio Chagas. "Tradição religiosa afro-brasileira como espaço de equilíbrio". In: SILVA, José Marmo da (org.). Religiões Afro-Brasileiras e Saúde. São Luís: Ató-Ire/Centro de Cultura Negra do Maranhão, p. 41-51, 2003.

INIESTA, Ferran. El Pensamiento Tradicional Africano: Retorno al Planeta Negro. Madrid: Casa África, 2010.

JAGUN, Márcio de. Ewé: a chave do portal. Rio de Janeiro, Litteris, 2019.

LEMOS, Kaio. No candomblé, quem é homem e quem não é? Rio de Janeiro: Metanoia, 2019.

LIMA, Vivaldo da Costa. A Família de Santo nos Candomblés Jêjes-Nagôs da Bahia. Salvador: Corrupio, 2003. 
MANDARINO, Ana Cristina de Souza; GOMBERG, Estélio. "Candomblé, corpos e poderes". Perspectivas, v. 43, p. 199-217, jan./jun. 2013.

OYĚWÙMÍ, Oyèrónkẹ. The Invention of Women: Making an African Sense of Western Gender Discourses. Minneapolis: University of Minnesota Press, 1997.

PEREIRA, Hanayrá Negreiros de Oliveira. $O$ axé nas roupas: indumentárias $e$ memórias negras no candomblé angola do Redandá. Dissertação (Mestrado em Ciências da Religião). Programa de Pós-Graduação em Ciências da Religião. São Paulo: PUC-SP, 2017.

SOUZA, Gilda de Mello e. O Espírito das roupas: a moda no século XIX. São Paulo: Companhia das Letras, 1987.

SOUZA, Patrícia Ricardo de. Axós e Ilequês: Rito, mito e estética do candomblé. Tese (Doutorado em Sociologia). Programa de Pós-Graduação em Sociologia. São Paulo: Universidade de São Paulo, 2007.

SERANO, Julia. Whipping Girl: A Transsexual Woman on Sexism and the Scapegoating of Femininity. Berkeley: Seal Press, 2007.

Recebido em: 17/11/2019 Aceito em: 25/11/2019 